\title{
Vibrational Spectroscopy and Density Functional Theory Study of 5-Amino-2-Mercaptobenzimidazole
}

\author{
Yufeng Chen
}

Chemistry and Chemical Enginering, Mudanjiang normal university, heilongjiang Mudanjiang,

157012, P. R. China.

\begin{abstract}
The geometrical structure of 5-amino-2-mercaptobenzimidazole (5A2MBI) was done and the corresponding structural parameters were calculated on the basis of the calculation by using B3LYP/6-311G (d, p) level, The FT-IR and Raman spectra of 5A2MBI were recorded in the solid phase, the results are compared with the theoretical spectrum calculated by using B3LYP/6-311G $(d, p)$ level, our calculated results are in good agreement with the experimental values. The assignments of the vibrational spectra on $5 \mathrm{~A} 2 \mathrm{MBI}$ are well resolved and accurately assigned on the basis of the results of the potential energy distribution (PED) which was carried out by the VEDA 4 program. Besides, The Frontier molecular orbitals, UV-Vis spectrum were investigated using theoretical calculations.
\end{abstract}

Keywords: Vibrational spectroscopy; FT-IR Raman spectra; density functional theory (DFT); 5amino-2-mercaptobenzimidazole (5A2MBI).

\section{Introduction}

The recent literature reports that benzimidazole derivatives are involved in a wide range of therapeutic areas make them compounds of a growing interest. Benzimidazole compounds belong to heterocyclic compounds which possesses a special structure (delocalized $\pi$ bond system and active nitrogen and sulfur atoms), which exhibit a large range of biological activities, it is especially suitable be used as antihypertensive [1], antiparasitic [2-4], anticancer [5], antibacterial, antifungal [6-10], corrosion inhibitor agent, coating agent of metallic surfaces and antioxidant in rubber industry [1115]. Use of these chemical compounds is widespread and they are well known toxic and poorly biodegradable pollutants. Such chemicals are frequently released to the environment and could be found in effluent of wastewater treatment plants and surface waters [16-19].

DFT includes electron correlation in the self-consistent Kohn-Sham procedure through the functions of electron density, so it is a cost and reliable method [20-21]. Vibrational spectroscopy has been extensively used for structural characterization of molecular systems by DFT calculations [2228]. DFT has been successfully applied to the description of the vibrational properties of many molecules, including heterocycles [29-32].

In this work, the UV, FT-IR, and FT-Raman spectra of 5A2MBI were investigated. The assignments of the vibrational spectra on $5 \mathrm{~A} 2 \mathrm{MBI}$ are well resolved and accurately assigned on the basis of the calculation by using B3LYP/6-311G(d,p) level. The calculations are valuable to take insight into the vibrational spectroscopy and molecular parameters of 5A2MBI structure.

\section{Experimental}

\subsection{Materials}

5A2MBI was purchased from Aldrich, All other analytical grade chemicals were purchased from Beijing Chemical Reagent Factory and used without further purification.

\subsection{Instruments}

Raman Spectra of 5A2MBI were recorded on a LabRam Aramis Raman Microscope system (Horiba-JobinYvon) equipped with a multichannel air cooled charge-coupled device (CCD) detector. Spectra were excited using the $633 \mathrm{~nm}$ excitation line of a He-Ne narrow bandwidth laser (Melles Griot). The Raman spectra were collected with the laser power at the sample position typically at 400 
$\mu \mathrm{W}$ with an average spot size diameter of $1 \mu \mathrm{m}$. The typical acquisition time used in this work was 10s. The FT-IR spectra of 5A2MBI were recorded as KBr disks at room temperature by a Nicolet iS10 FT-IR spectrometer, equipped with a DTGS detector at a resolution of $4 \mathrm{~cm}^{-1}$.

\subsection{Theoretical Method}

The molecular structure of 5A2MBI in the ground state is optimized using Gaussian 09 suite of program by B3LYP with the 6-311G $(\mathrm{d}, \mathrm{p})$ basis set, which is the hybrid of Beckes's three-parameter exchange functional with the Lee-Yang-Parr correlation functional. The vibrational frequencies of 5A2MBI were calculated at the same level. The potential energy distribution (PED) calculation was carried out by the VEDA 4(Vibrational Energy Distribution Analysis) program [33, 34]. The method for calculating scaling factors was same as that proposed by Scott and Radom [35].

\section{Results and Discussion}

\subsection{Geometrical Structure}

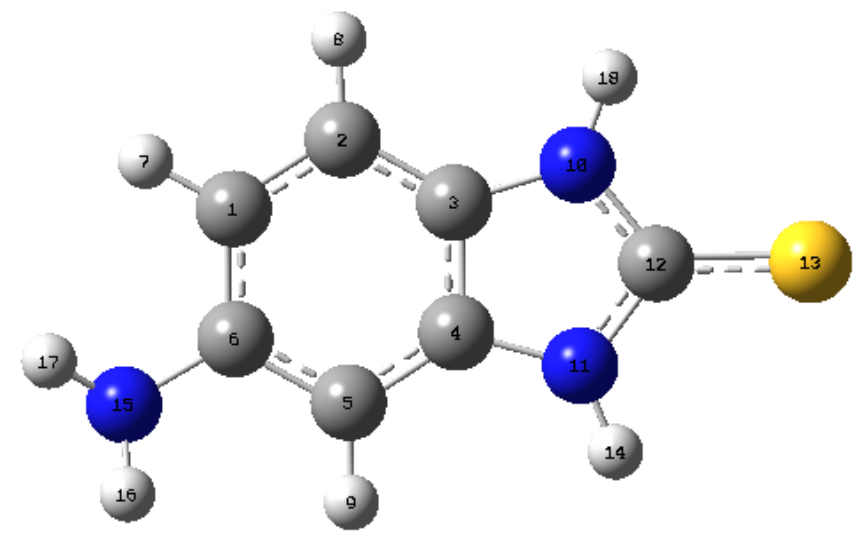

Fig. 1 The Molecular Structures and Numbering of the Atoms of 5A2MBI

The DFT [B3LYP/6-311G $(\mathrm{d}, \mathrm{p})$ ] methods were used in geometrical optimization of the 5A2MBI molecule. The atom numerical labels in the following discussion refer to Fig.1.

The dihedral angle of 5A2MBI showed they were planar or close to planar structure. There were no imaginary frequency in the theoretical results showed that the optimized geometry of $5 \mathrm{~A} 2 \mathrm{MBI}$ is stable.

\subsection{Vibrational Assignments}

According to the theoretical calculations, $5 \mathrm{~A} 2 \mathrm{MBI}$ belongs to $\mathrm{C} 1$ point group symmetry, thus all the frequency modes are produced in a species. The molecule has 18 atoms and a total of 48 vibrations are then expected, these modes are found to be active both in the Raman scattering and infrared absorption. 


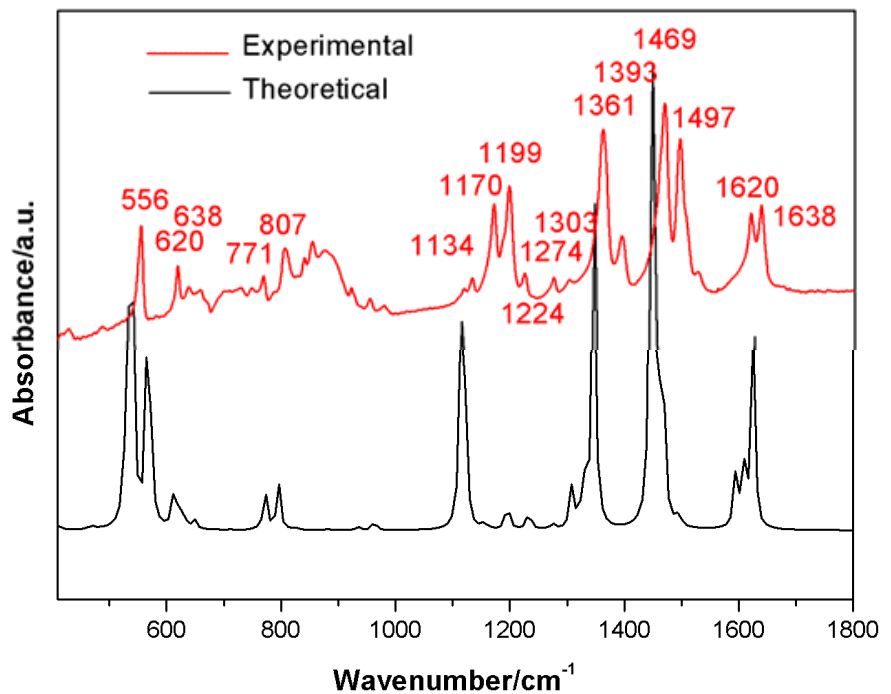

Fig. 2. The Comparison of the Experimental FT-IR Spectrum (red) of 5A2MBI with the Theoretical IR Spectrum (Black, B3LYP/6-311G**).

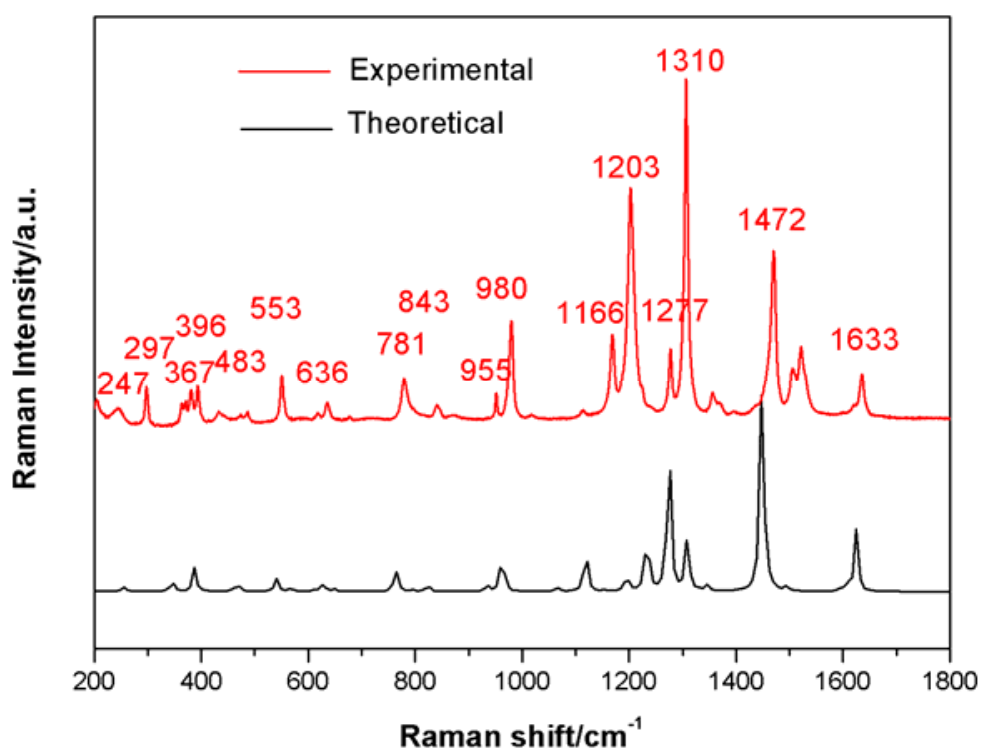

Fig.3. The Comparison of the Experimental Rman Spectrum (red) of 5A2MBI with the Theoretical Raman Spectrum (Black, B3LYP/6-311G**).

\section{$3.3-\mathrm{NH}_{2}$ Vibrations}

According to Socrates [36], the frequencies of amino group appear around $3500-3300 \mathrm{~cm}^{-1}$ for $\mathrm{NH}_{2}$ stretching, $1700-1600 \mathrm{~cm}^{-1}$ for scissoring and 1150-900 $\mathrm{cm}^{-1}$ for rocking deformations. The scaled $\mathrm{NH}_{2}$ asymmetric and symmetric stretching modes of 5A2MBI are calculated at $3542 \mathrm{~cm}^{-1}$ and 3449 $\mathrm{cm}^{-1}$, respectively. The $\mathrm{NH}_{2}$ scissoring frequency is found at $1610 \mathrm{~cm}^{-1}$, The $\mathrm{NH}_{2}$ wagging predicted at $568 \mathrm{~cm}^{-1}$, the torsional modes of $\mathrm{NH}_{2}$ is found at $250 \mathrm{~cm}^{-1}$.

\section{4 $-\mathrm{C}=\mathrm{S}$ Vibrations}

Compounds that contain a thiocarbonyl group show absorption in the $1250-1020 \mathrm{~cm}^{-1}$ region. Thiobenzophenone and its derivatives absorb moderately in the 1224-1207 cm-1 region. According to our calculation results, the vibrations containing contribution from the $\mathrm{C}=\mathrm{S}$ bond at $388,541,765$, $825,963,1115,1122$, and $1598 \mathrm{~cm}^{-1}$.Spectra of compounds in which the $\mathrm{C}=\mathrm{S}$ group is attached to a nitrogen atom show an absorption band in the general $\mathrm{C}=\mathrm{S}$ stretching region. Very strong couplings exist when a $\mathrm{C}=\mathrm{S}$ group is attached to one or two nitrogen atoms. In addition, several other bands in the broad region of $1563-700 \mathrm{~cm}^{-1}$ can be attributed to vibrations involving interaction between $\mathrm{C}=\mathrm{S}$ 
stretching and C-N stretching. 1115 and $1122 \mathrm{~cm}^{-1}$ band of the 5A2MBI was assigned as $\mathrm{v} C \mathrm{C}(16)+$ $v \mathrm{CS}(9)+\delta \mathrm{CH}(40)+\delta \mathrm{NH}(18)$ and $v \mathrm{CC}(15)+v \mathrm{CS}(21)+\delta \mathrm{NH}(30)+\delta \mathrm{CH}(17)$ respectively.

\subsection{Benzimidazole Ring Vibrations}

Skeletal vibrations, involving $\mathrm{C}=\mathrm{C}$ and $\mathrm{C}=\mathrm{N}$ stretching modes within the ring, absorb in the $1200 \sim 1500 \mathrm{~cm}^{-1}$ region are splitted slightly. $1157 \mathrm{~cm}^{-1}$ in the spectrum may be assigned to C-N stretching and C-H, N-H in plane bending modes; $1276 \mathrm{~cm}^{-1}, 1310 \mathrm{~cm}^{-1}$ and $1627 \mathrm{~cm}^{-1}$ assigned to C$\mathrm{C}$ stretching and $\mathrm{C}-\mathrm{C}-\mathrm{C}$ in plane bending mode; $1450 \mathrm{~cm}^{-1}$ raman band assigned to $\mathrm{C}-\mathrm{C}$ stretching and $\mathrm{C}-\mathrm{H}, \mathrm{N}-\mathrm{H}, \mathrm{C}-\mathrm{C}-\mathrm{C}$ in plane bending modes.

\subsection{Frontier Molecular Orbitals}

Both the highest occupied molecular orbital (HOMO) and lowest unoccupied molecular orbital (LUMO) and their properties such as energy are very useful for chemical reaction.

The energy gaps results in a significant degree of electric excitation and charge transfer which are responsible for the chemical and spectroscopic properties of the molecules. This is also used by the frontier electron density for predicting the most reactive position in $\pi$-electron systems and also explains several types of reaction delocalized system. The HOMO is delocalized over $-\mathrm{C}=\mathrm{S}$ group, nitro group. The HOMO $\rightarrow$ LUMO transition implies an electron density transfer to benzimidazole ring through $\mathrm{C}-\mathrm{S}$ and $\mathrm{C}-\mathrm{N}$ bond from $\mathrm{S}$ and $\mathrm{N}$ atom. The HOMO $\rightarrow$ LUMO gap estimated to be $4.36 \mathrm{ev}$ at the B3LYP/6-311G** level and the frontier orbitals are illustrated in Fig.4.

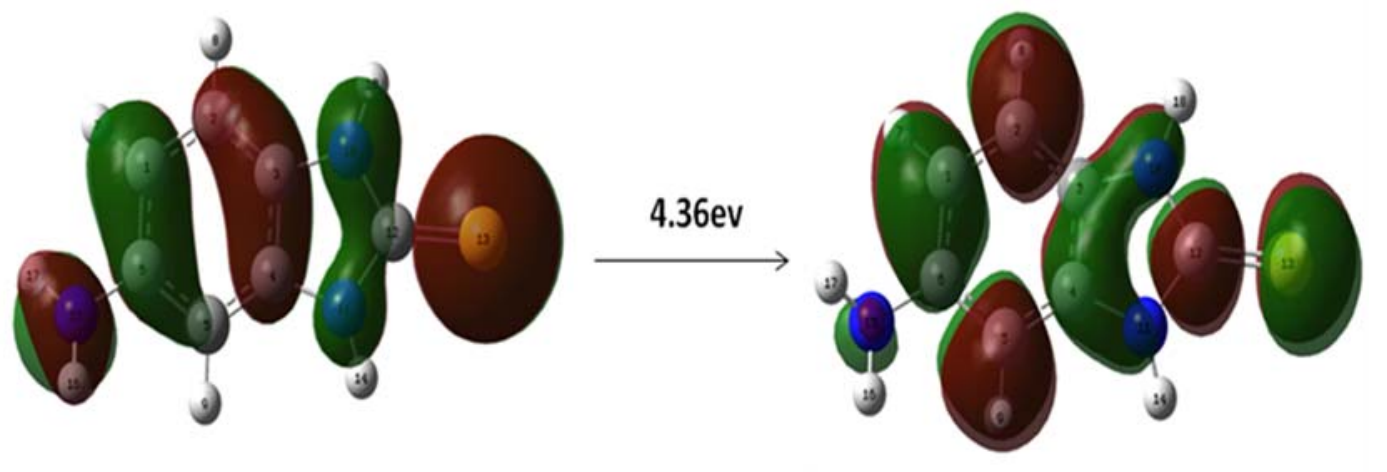

Fig.4. Plots of the Frontier Molecular Orbitals of 5A2MBI Calculated at B3LYP/6-311 G** Level

\subsection{UV-Vis Spectrum}

The experimental and theoretical UV-Vis spectra are shown in Fig. 5. Experimental and theoretical maximum absorption wavelengths, excitation energy, oscillator strength are collected in Table 1 . The observed peaks were found at 251 and $315 \mathrm{~nm}$ comparison with the calculated peaks were found at 244 and $314 \mathrm{~nm}$, which may have been caused by the error of PCM modeling.

Table 1. Experimental and Theoretical Wavelengths $\lambda(\mathrm{nm})$, Excitation Energies (eV), and Oscillator Strengths $(f)$ in Gas Phase of 5A2MBI.

\begin{tabular}{cccccc}
\hline theoretical & & & & \multicolumn{2}{c}{ Experimental } \\
\hline$\lambda / \mathrm{nm}$ & $\mathrm{E} / \mathrm{eV}$ & $f$ & $\begin{array}{c}\text { Major contribution } \\
\text { HOMO-2 } \rightarrow \text { LUMO }(40.5 \%)\end{array}$ & $\lambda / \mathrm{nm}$ & $\mathrm{E} / \mathrm{eV}$ \\
244 & 5.08 & 0.202 & $\begin{array}{c}\text { HOMO } \rightarrow \text { LUMO+1(31.7\%) } \\
\text { HOMO } \rightarrow \text { LUMO }+1(80.4 \%)\end{array}$ & 251 & 4.95 \\
311 & 4.00 & 0.366 & HOM & 351 & 3.54 \\
\hline
\end{tabular}




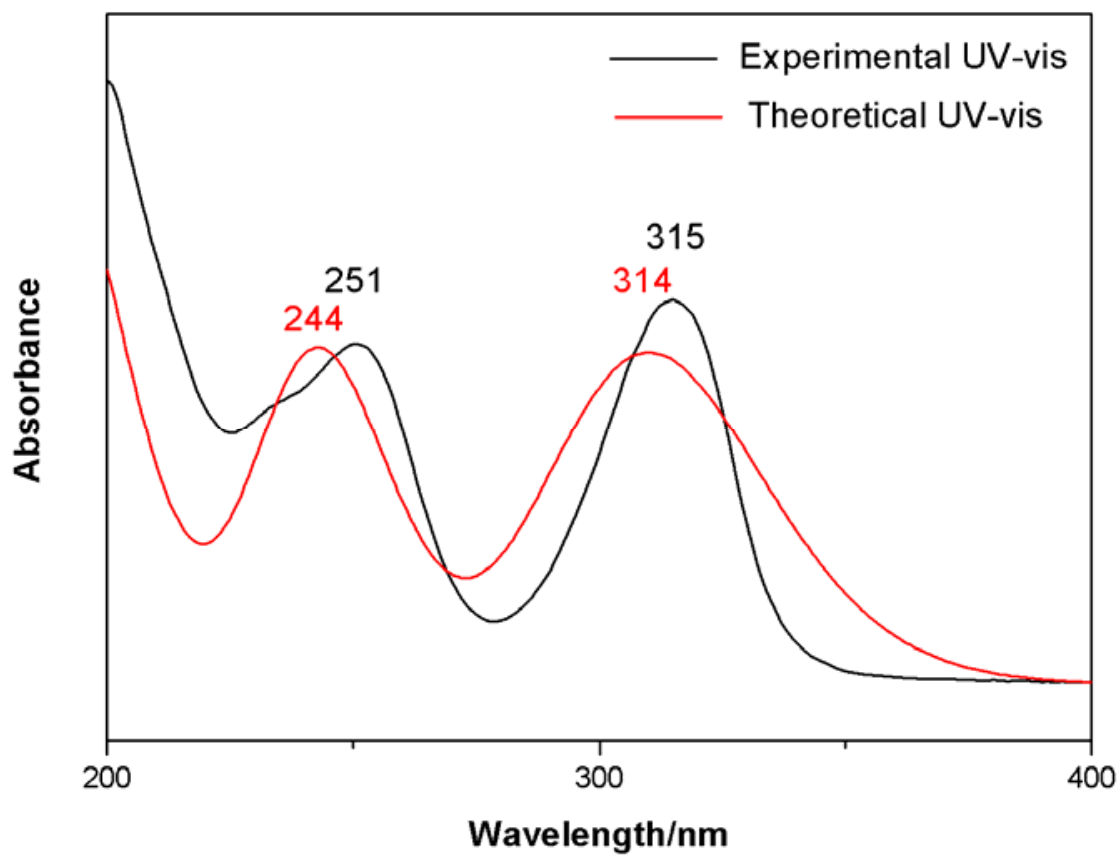

Fig. 5.The Comparison of the Experimental (Black) and Theoretical UV-Vis spectra (Red) of $5 \mathrm{~A} 2 \mathrm{MBI}$

\section{Conclusion}

The geometrical structure of 5-amino-2-mercaptobenzimidazole (5A2MBI) was done and the corresponding structural parameters were calculated on the basis of the calculation by using B3LYP/6-311G (d, p) level, The FT-IR and Raman spectra of 5A2MBI were recorded in the solid phase, the results are compared with the theoretical spectrum calculated by using B3LYP/6-311G (d, p) level, our calculated results are in good agreement with the experimental values. The assignments of the vibrational spectra on 5A2MBI are well resolved and accurately assigned on the basis of the results of the potential energy distribution (PED) which was carried out by the VEDA 4 program. HUMO and LUMO orbitals have been visualized, it has been conclude that the HOMO $\rightarrow$ LUMO transition implies an electron density transfer to benzimidazole ring through $\mathrm{C}-\mathrm{S}$ and $\mathrm{C}-\mathrm{N}$ bond from $\mathrm{S}$ and $\mathrm{N}$ atom. The HOMO $\rightarrow$ LUMO gap estimated to be $4.36 \mathrm{ev}$ at the B3LYP/6-311G** level. The $\mathrm{UV}-\mathrm{V}$ is spectrum observed peaks were found at 251 and $315 \mathrm{~nm}$ comparison with the calculated peaks were found at 244 and $314 \mathrm{~nm}$.

\section{Acknowledgements}

Research record project of the Education Department of Heilongjiang Province (1352MSYYB012, 1351MSYZD003); Heilongjiang Provincial key innovation prediction project (SY2014003); Youth general project (QY201215); Doctoral Research Fund of Mudanjiang Normal University (MNUB201612); National training program (GP201616).

\section{References}

[1]. S. Nagarajan, S. Majumder, U. Sharma, S. Rajendran, N. Kumar, S. Chatterjee, B. Singh, Bioorg. Med. Chem. Lett. 23(2013) 287-290.

[2]. T. Boontongto, Y. Santaladchaiyakit, R. Burakham, Chromatographia 77(2014) 1557-1562.

[3]. Y. Santaladchaiyakit, S. Srijaranai, R. Burakham, Food Anal. Methods 7(2014) 1973-1981.

[4]. J. Vichapong, Y. Santaladchaiyakit, R. Burakham, S. Srijaranai, Anal. Lett. 48(2015) 617-631. 
[5]. T. Yamano, T. Noda, M. Shimizu, S. Morita, Fundam. Appl. Toxicol. 25(1995) 218-223.

[6]. J. P. Seiler. Mutation Research 32(1975)151-168.

[7]. M. S. Kim, M. K. Kim, C. J. Lee, Y. M. Jung, M. S. Lee, Bull. Korean Chem. Soc. 30(2009) 2930-2934.

[8]. Y. Santaladchaiyakit, S. Srijaranai, Sep. Sci. 37(2014) 3354-3361.

[9]. R. K. Shervedani, F. Yaghoobi, A. Hatefi-Mehrjardi, S. M. Siadat-Barzoki, Electrochim. Acta 53 (2008) 4185-4192.

[10]. X. J. Deng, X. P. Chen, K. Lin, G. S. Ding, P. Yao, Food Anal. Methods 6(2013) 1576-1582.

[11]. P. G. Cao, R. A. Gu, Z. Q. Tian, Langmuir 18(2002) 7609-7615.

[12]. T. C. Keith, G. Xue, L. L. Mary. Langmuir 7(1991) 2-4.

[13]. D. Q. Zhang, L. X. Gao, G. D. Zhou, J. Appl. Electrochem. 33(2003) 361-366.

[14]. G. Wang, A. Harrison, X. Li, G. Whittaker, J. Shi, X. Wang, H. Yang, P. Cao, Z. Zhang, J. Raman Spectrosc. 35(2004) 1016-1022.

[15]. E. Lipka, J. Charton, C. Vaccher, Biomed. Chromatogr. 28(2014) 4-9.

[16]. H. Parham, F. Khoshnam, Talanta 114(2013) 90-94.

[17]. S. Rastegrzadeh, Z. B. Rezaei, Environ. Monit. Assess. 185(2013) 9037-9042.

[18]. B. Abolghasem, R. siavash, P. Eslam, R. Mohanmmad, N. Parviz, J. Food Sci. 75(2010) 135139.

[19]. H. Parham, F. Khoshnam, Talanta, 114(2013) 90-94.

[20]. A. D. Becke, Phys. rev. A 38 (1988) 3098-3100.

[21]. A. D. Becke, J. Chem. Phys. 98(1993) 5648-5652.

[22]. L. L. Mary, L. Lars, T. C. Keith, Langmuir 9(1993) 186-191.

[23]. M.W. Wong, Chem. Phys. Lett. 256(1996)391-399.

[24]. Y. X. Yuan, P. J. Wei, W. Qin, Y. Zhang, J. L. Yao, R. A. Gu, Euro. J. Inorg. Chem. 2007(2007) 4980-4987.

[25]. H. L. Zheng, S. S. Yang, J. Zhao, Z. C. Zhang, Appl. Phys. A 114(2014) 801-808.

[26]. G. Xue, Y. Lu, Langmuir 10(1994) 967-969.

[27]. H. Y. H. Chan, M. J. Weaver, Langmuir 15(1999) 3348-3355.

[28]. S. Suresh, K. Jayamoorthy, P. Saravanan, S. Karthikeyan, Sensor Actuat. B 225 (2016) 463468

[29]. Th. Doneux, F. Tielens, P. Geerlings, Cl. Buess-Herman, J. Phys. Chem. A 110(2006) 11346-11352.

[30]. N. Sundaraganesan, B. Dominic Joshua, K. Settu, Spectrochim. Acta A 66 (2007)381-388.

[31]. R. Li, W. Ji, L. Chen, H. M. Lv, J. B. Cheng, B. Zhao, Spectrochim. Acta A 122 (2014) 698703.

[32]. Y. F. Chen, J. Yang, Z. L. Li, R. Li , W. D. Ruan, Z. P. Zhuang, B. Zhao, Spectrochim. Acta A 153(2016) 344-348.

[33]. M. H. Jamróz, Spectrochim. Acta. A 114(2013)220-230. 
[34]. M. H. Jamróz, Vbrational Energy Distribution Analysis VEDA 4 program. Warsaw, 2004.

[35]. J. P. Merrick, D. Moran, L. Radom, J. Phys. Chem. A 111(2007)11683-11700.

[36]. G. Socrates, Infrared and Raman Characteristic Group Frequencies, Tables and Charts, 3rd ed., Wiley, Chichester, 2001. 